\title{
Editorial on the special issue of Heat and Mass Transfer (Springer) after the $3^{\text {rd }}$ Iranian Conference on Heat and Mass Transfer
}

\author{
Mostafa Safdari Shadloo ${ }^{1}$ (D)
}

Received: 4 June 2019 / Accepted: 6 June 2019 / Published online: 19 June 2019

(C) Springer-Verlag GmbH Germany, part of Springer Nature 2019

This special issue of Heat and Mass Transfer contains 18 articles that are selected from the presented papers in the 3rd Iranian Conference on Heat and Mass Transfer, held in Babol, Iran, from November 22 to 23, 2017.

To form this special issue, the articles were first selected by scientific committee based on the comments gathered from 2 or 3 reviewers for the conference. After announcement of the top articles, the authors extended their papers and submitted them to the usual peer-review process of the journal, which included at least two independent reviewers. The articles that are published in this special issue are the result of an excerpt from more than 300 articles presented orally or by posters at the conference.

In recent years, the emphasis on improving heat transfer in engineering and industry sciences is growing at high speeds, which has now become a very important part of empirical and theoretical research. Improvement of heat transfer using conventional methods has resulted in significant savings in costs and energy sources and environmental protection. The papers cover vast topics of heat and mass transfer which are listed below.

This issue contains some fundamental investigations of heat and mass transfer science related to internal flow (Khanmohammadi et al.; Amiri et al.; Ganjbakhsh et al.;

Mostafa Safdari Shadloo

msshadloo@coria.fr

1 CORIA Lab. / CNRS-UMR 6614, University and INSA of Rouen, Normandy University, 76000 Rouen, France
Shafipour et al.) and natural convection (Davoodi et al.; Hooman et al.). There are also some studies in this issue which are dedicated to optimization process related to nanofluid and thermodynamic topics (Sheikhzadeh et al.; Dadsetani et al.). Another paper in this issue is on the turbulence topic in the field of supersonic boundary layers (Sharma et al.).

Heat and mass transfer play the main role for any improvement in modernization. Its applications can be seen in a variety of contexts. Different approaches have been proposed to improve the combustion process and decrease pollutants in internal combustion engines (Marrero-Santiago et al.; Pourfallah and Armin; Fordoei and Mazaheri; Mulla et al.). Moreover, several studies are dedicated to enhance the heat transfer by numerical and/or experimental methods related to air conditioning, casting, osmotic dehydration, porous media and turbulence (Afzal et al.; Javahery and Abbasi; Nazari et al.; Hoseini Larimi et al.; Mohajer and Niknam Shahrak; Sharma et al.;).

As the Guest Editor of this special issue of Heat and Mass Transfer, I would like to thank from the Babol Noshirvani University of Technology for conference holding and also all authors who contributed suitable papers in the special issue and thank all of the reviewers who had provided their critical comments. A special thanks to the journal Editor-in-Chief, Prof. Andrea Luke, for giving us this opportunity to edit the special issue.

Publisher's note Springer Nature remains neutral with regard to jurisdictional claims in published maps and institutional affiliations. 